
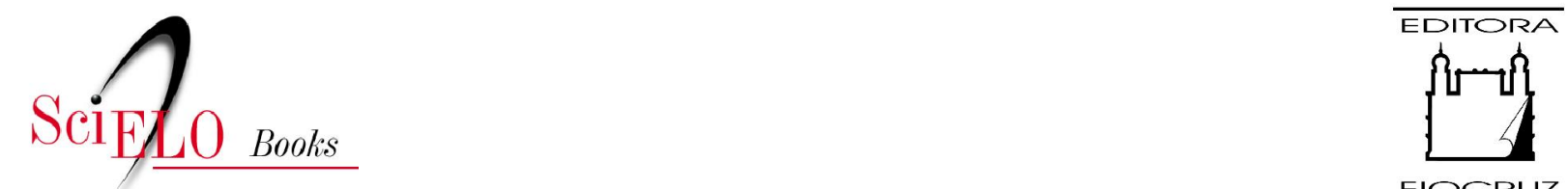

FIOCRUZ

\title{
El rol de la mediación estratégica en las arenas de interacción para la potenciación del intercambio lingüístico-cultural
}

\author{
Fábio Marques de Souza \\ Ana Luzia de Souza \\ Angela Patricia Felipe Gama
}

\section{SciELO Books / SciELO Livros / SciELO Libros}

SOUZA, F. M., SOUZA, A. L., and GAMA, A. P. F. El rol de la mediación estratégica en las arenas de interacción para la potenciación del intercambio lingüístico-cultural. In: SOUZA, F. M., and ARANHA, S. D. G., orgs. Interculturalidade, linguagens e formação de professores [online]. Campina Grande: EDUEPB, 2016, pp. 145-171. Ensino e aprendizagem collection, vol. 2. ISBN 97885-7879-347-0. Available from: doi: 10.7476/9788578793470.0008. Also available in ePUB from: http://books.scielo.org/id/qbsd6/epub/souza-9788578793470.epub.

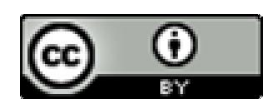

All the contents of this work, except where otherwise noted, is licensed under a Creative Commons Attribution 4.0 International license.

Todo o conteúdo deste trabalho, exceto quando houver ressalva, é publicado sob a licença Creative Commons Atribição 4.0.

Todo el contenido de esta obra, excepto donde se indique lo contrario, está bajo licencia de la licencia Creative Commons Reconocimento 4.0. 


\section{EL ROL DE LA MEDIACIÓN ESTRATÉGICA EN LAS ARENAS DE INTERACCIÓN PARA LA POTENCIACIÓN DEL INTERCAMBIO LINGÜÍSTICO-CULTURAL ${ }^{1}$}

Fábio Marques de Souza (UEPB/UFPE)

Ana Luzia de Souza (UEPB/IFPB)

Angela Patricia Felipe Gama (PUC-SP)

Antes de ser profesores, fuimos y somos aprendices de idiomas $\mathrm{y}$, por consiguiente, hablantes de lenguas. Por tanto, tenemos consciencia de la dificultad que existe respecto a la adquisición de la oralidad en una lengua adicional (LA). Podemos afirmar que esta competencia es una de las más complejas o, quizás, la más difícil de adquirirse. En este sentido, Revuz (1998) expone:

Objeto de conocimiento intelectual, la lengua es también objeto de una práctica. Esa práctica es, por sí sola,

1 Agradecemos a los amigos Prof. Dr. Manoel Dias Martins y Yendrys Martínez Martínez por la revisión crítica de este texto. 
compleja. Práctica de expresión, relativamente creativa, convoca al sujeto, a su manera de relacionarse con los demás y con el mundo; una práctica corporal, pues pone en juego todo su aparato fonador. (...) El sujeto debe poner al servicio de la expresión de su yo un vaivén que requiere mucha flexibilidad psíquica entre un trabajo del cuerpo sobre los ritmos, los sonidos, las curvas de entonación, y un trabajo de análisis y de memorización de las estructuras lingüísticas. Es posible plantear la hipótesis de que muchos de los fracasos pueden ser analizados como una incapacidad de relacionar esos tres elementos: afirmación del yo, trabajo del cuerpo, dimensión cognitiva (REVUZ, 1998, p.216-217).

Tenemos consciencia de las dificultades en cuanto a la interacción oral en situaciones reales de comunicación en la lengua meta y, como profesores, somos conscientes también de nuestra función como agentes de humanización en el trabajo con el lenguaje. De esa manera, iniciaremos este texto presentando dos de los participantes que nos motivan a desarrollar nuestras prácticas e investigaciones y que, por tanto, dan significado a nuestras acciones en la enseñanza, en la investigación y en la extensión. 


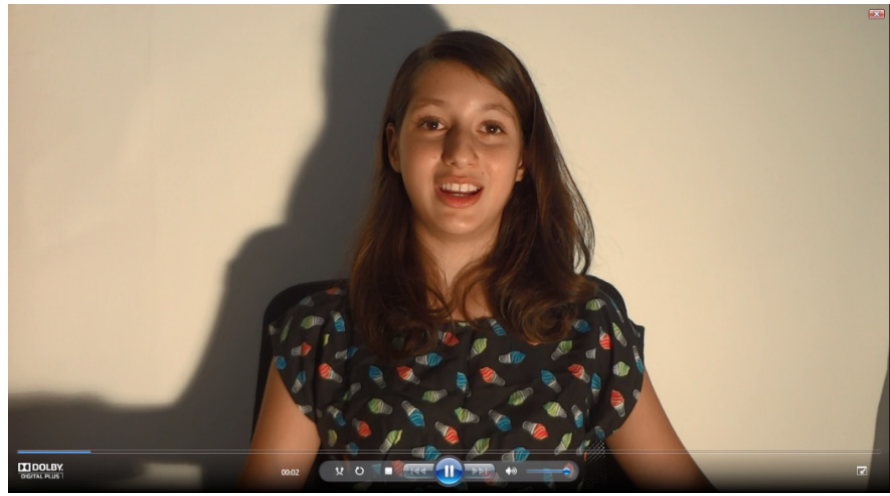

Imagen 1 - Pantalla inicial del video de presentación de Nathália, grabado en español- LA, para participación en el proyecto "INTERCULT: aprendizaje colaborativo e intercultural de lenguas vía teletándem"

Fuente: corpus reunido durante el desarrollo del proyecto "INTERCULT".

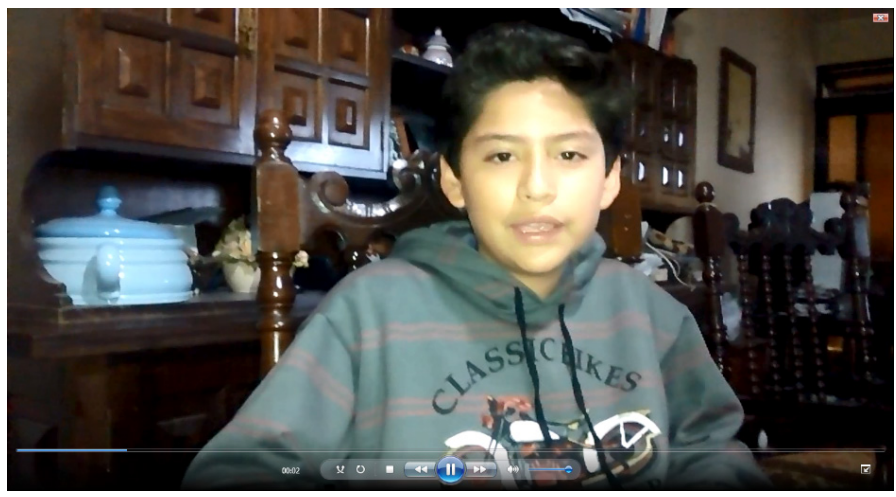

Imagen 2 - Pantalla inicial del video de Santino, grabado en portugués - LA, para participación en el proyecto "INTERCULT: aprendizaje colaborativo e intercultural de lenguas vía teletandem"

Fuente: corpus reunido durante el desarrollo del proyecto "INTERCULT". 
Nathália es brasileña, vive en el interior del Estado de Paraíba, Brasil. Tiene 12 años, cursa el 7. ${ }^{\circ}$ año de la enseñanza fundamental y estudia español. Empezó a estudiar esta LA en la escuela; participó en un curso de extensión en la UEPB y, actualmente, además de las clases regulares en el colegio, estudia en casa. Santino es argentino, vive en la Provincia de Salta, tiene la misma edad de Nathália y también es alumno de la enseñanza fundamental. Estudia portugués como LA hace 4 años, en un centro de idiomas subvencionado por el gobierno de Salta, en Argentina. Pese a que uno estudia la lengua del otro, difícilmente los dos podrían encontrarse para prácticas reales de uso de la lengua meta de cada uno, de manera que fuese promovido el avance de sus habilidades orales con el apoyo de un mediador.

El encuentro de los dos aprendientes ${ }^{2}$ fue posible a partir de la mediación con el apoyo de las Tecnologías Digitales de la Información y Comunicación (TDICS) y de profesores investigadores, realizadores del proyecto interinstitucional "INTERCULT: aprendizaje colaborativo e intercultural de lenguas vía teletándem", actividad colaborativa entre la Universidade Estadual da Paraíba, Universidade Federal de Pernambuco, Instituto Federal da Paraíba, Universidade Federal da Integração

2 Compartimos, en este texto, el término aprendiente presentado por Garcia de Stefani (2010, p.59) por ser formado del prefijo aprend - del verbo aprender y el sufijo -iente - que designa aquel que practica la acción, resaltando, de este modo, el carácter activo de aquel que aprende. 
Latino-Americana, Universidad Nacional de Rosario y del Instituto de Idiomas de Salta ${ }^{3}$ (Argentina).

A pesar de poco conocida, la práctica del teletándem es antigua, existe en muchos países, incluso en Brasil, con trabajos desarrollados por la Universidade Estadual Paulista (UNESP) y la Universidade Federal do Paraná (UFPR), por ejemplo.

La propuesta apunta a fomentar el intercambio lingüístico-cultural entre los estudiantes que tienen el portugués y el español como lenguas adicionales. De acuerdo con Souza (2015a), utilizaremos, a lo largo de este capítulo, el término "adicionales", y no "extranjeras", cuando se hace referencia a lenguas no maternas porque consideramos que el término "extranjero" tiene connotaciones que remiten a lo que es ajeno, diferente, opuesto.

Compartiendo la cita de Almeida Filho (1993) cuando dice que aprender una lengua extranjera "es crecer en una matriz de relaciones interactivas en la lengua meta que gradualmente se desextranjeriza para quien la aprende" (p.15) y considerando que la lengua, para ser aprendida/ adquirida ${ }^{4}$ necesita desextranjerizarse en un complejo continuum, juzgamos más adecuado nombrarla como lengua adicional (LA) y no extranjera.

3 Colaboración mediada por la profesora Liliana Roxana Rubín, Instituto de Idiomas de Salta, n. ${ }^{\circ}$ 7216, subvencionada por la gestión pública de educación no formal del Ministerio de Educación.

4 Los términos adquisición y aprendizaje se utilizarán, en este texto, indistintamente pese a las discusiones alrededor de esta temática, así como la dicotomía establecida por Krashen (1982). 


\section{Latinoamérica como una construcción cultural, histórica, política y no solo una construcción geográfica}

La proposición del teletándem interinstitucional, que se está desarrollando como proyecto de enseñanza, investigación y extensión, comprende lo lingüístico como elemento fundamental en el proceso de integración regional $\mathrm{y}$, de este modo, el español y el portugués son pensados como lenguas adicionales multidimensionales e interculturales de forma a promover una integración que considere Latinoamérica como construcción cultural, histórica, política y no solamente construcción geográfica (SOUZA, 2014).

De entre los diversos temas de estudio que han surgido a partir del proyecto, tenemos por objetivo investigar el rol de la mediación y su influencia en la percepción que los interactuantes tienen de su proceso de aprendizaje de lenguas y potencializar la interacción oral y cultural de los aprendientes en un contexto de no inmersión, usando el teletándem como forma de interacción. Específicamente, los objetivos son los siguientes:

- Perfeccionar la interacción oral de los interactuantes;

- Crear un corpus representativo de conversaciones mediadas por el teletándem;

- Generar datos, por medio de análisis cualitativo, de las estrategias conversacionales entre hablante nativo/ hablante no nativo;

- Crear un banco de datos para una posible elaboración de un manual de procedimientos de implantación del teletándem en escuelas y universidades. 
Convivimos con un presunto discurso de integración latinoamericana, que hace mucho tiempo permea nuestros textos oficiales, al lado de claras evidencias de imperialismo y colonización lingüística que convierten esas leyes en letras muertas.

La Constitución de 1988, en su artículo $4 .^{\circ}$, párrafo único, presenta: “ $\mathrm{La}$ República Federativa de Brasil buscará la integración económica, política, sociocultural de los pueblos de Latinoamérica, con miras a la formación de una comunidad latinoamericana de naciones". Sin embargo, nuestra historia fue marcada por un recorrido que confirma la falta de compromiso con una política que, de hecho, se haya dedicado a la construcción de una relación dialéctica entre Brasil y los países hispánicos. Desde el Tratado de Tordesillas, nosotros y nuestros vecinos hispanoamericanos vivimos de espaldas los unos a los otros. Nuestras miradas estuvieron durante muchos años volcadas hacia Europa, representada por los modelos culturales de París y/o Londres y, años más tarde, volvimos nuestra atención hacia 
Norteamérica (SOUZA, 2014, p.114, traducción nuestra). ${ }^{5}$

Según expone Souza (2009), presenciamos, en 1991, la firma del Tratado de Asunción, instrumento jurídico fundamental del Mercosur, que deja claro, en su artículo $8 .^{\circ}$, tratarse de intereses comerciales, es decir, la constitución de un mercado común entre los países miembros: “de igual forma, tal como ocurre con el Tratado de Roma (25 de marzo de 1957) que instituye la creación de la actual Unión Europea, el Tratado de Asunción no propone objetivos culturales y lingüísticos" (CHAREILLE, 2003, p.66).

Arnoux (2010) analiza las representaciones sociolingüísticas y la construcción de identidades colectivas. Esta investigadora expone que el pueblo latinoamericano tendrá que ampliar sus identidades nacionales rumbo hacia una identidad que implica la consciencia de un destino común.

5 Traducción nuestra para: A Constituição de 1988, no seu artigo 4 , parágrafo único, apresenta: "A República Federativa do Brasil buscará a integração econômica, política, social e cultural dos povos da América Latina, visando à formação de uma comunidade latino-americana de nações". Porém, nossa história foi marcada por um percurso que confirma a falta de compromisso com uma política que, de fato, tenha se dedicado à construção de uma relação dialética entre o Brasil e os países hispânicos. Desde o tratado de Tordesilhas, nós e nossos vizinhos hispano-americanos vivemos de costas uns para os outros. Nossos olhares estiveram por muitos anos voltados à Europa, representada pelos modelos culturais de Paris e/ou Londres e, anos mais tarde, voltamos nossa atenção para a América do Norte (SOUZA, 2014, p.114). 
La construcción de una identidad colectiva impone la necesidad de políticas lingüísticas plurilingües sostenidas por políticas mediáticas y escolares que permitan a los futuros ciudadanos la comprensión mutua, para que puedan expresarse en otras lenguas y que sean capaces de elaborar estrategias lingüísticas de aprendizaje.

En este sentido, lo deseable es que las políticas lingüístico-culturales contemplen diversas modalidades de bilingüismo portugués-español y la convivencia con las lenguas de los pueblos originarios. El aprendizaje de la lengua del otro cumple una función decisiva no sólo porque permite ampliar las redes comunicativas, sino también por el juego de resonancias culturales a que cada lengua está asociada.

Tanto la legislación brasileña (Ley n. ${ }^{\circ}$ 11.161/2005) como la argentina (Ley n. ${ }^{\circ} 24.468 / 2009$ ), pueden considerarse como ejemplos de respuestas a las necesidades actuales de integración regional. Sin embargo, para que tales medidas no fracasen, son necesarias la concienciación y la actuación de la población de modo que esas políticas sean implantadas y se tornen, de hecho, públicas. En esta ocasión, es importante evaluar las creencias ${ }^{6}$ asociadas a las lenguas (SOUZA, 2015).

6 Adoptaremos la perspectiva sociocultural e interpretaremos las creencias como un elemento de la cognición. De este modo, compartiremos la definición de Barcelos (2006, p.18), que corrobora el sentido adoptado para nuestros estudios: "[Las creencias son] una forma de pensar, como construcciones de la realidad, formas de ver y percibir el mundo y sus fenómenos, coconstruídas en nuestras experiencias y como resultado de un proceso de interpretación y (re) significación. Como tal, las creencias son sociales (pero también individuales), dinámicas, contextuales y paradójicas". 
Ante lo expuesto, la integración regional puede ir más allá de la pauta meramente económica y, para consolidar la integración político-cultural, es fundamental la integración lingüística, que implica la sensibilización de la población para que esta adquiera conciencia de la importancia de tal hecho para el futuro de nuestros países. En tal dirección, el proyecto "INTERCULT: aprendizaje colaborativo e intercultural de lenguas vía teletándem" presenta sus contribuciones cuando favorece el intercambio lingüístico-cultural entre brasileños aprendientes de español e hispánicos aprendientes de portugués.

\section{Del tándem al teletándem}

A partir de una consistente revisión bibliográfica, Benedetti (2010) expone que, aunque poco conocido en Brasil, el aprendizaje de lenguas en tándem surgió en Alemania a finales de los años sesenta, diseminándose en las décadas siguientes por otros países de Europa como modalidad alternativa y complementaria al aprendizaje formal de lenguas adicionales (SOUZA, 2015b).

Inicialmente, el término tándem hacía referencia a una bicicleta para dos personas que dispone de dos sillines colocados el uno detrás del otro. Con el paso del tiempo, este término pasó a ser utilizado para definir un conjunto de dos personas que poseen una actividad en común o que colaboran en algo. En el campo de la enseñanza y aprendizaje de lenguas, "el aprendizaje en tándem consiste en el intercambio de conocimiento entre individuos 
de diferentes culturas, con propósitos de aprendizaje de lenguas de modo colaborativo" (BENEDETTI, p.21) .

Esta práctica se fundamenta en la concepción sociocultural del desarrollo humano y concibe, por tanto, el aprendizaje como un proceso socialmente mediado que fomenta la asociación entre personas que desean aprender una lengua adicional y que se ponen de acuerdo en alcanzar una meta por intermedio de prácticas con hablantes proficientes en el idioma que desean aprender. En otras palabras, se puede definir el aprendizaje en tándem como un proceso en que colaboran dos personas con diferentes lenguas maternas y que se ayudan mutuamente trabajando para incrementar los conocimientos idiomáticos, culturales $\mathrm{y}$, a veces, también para intercambiar otro tipo de información relacionada, por ejemplo, a sus respectivos estudios, gustos o áreas de interés o trabajo y que puede practicarse de modo presencial $u$ otro medio de comunicación.

Son características del aprendizaje en tándem: I) abierta, puesto que no sigue un programa curricular fijo; II) intercultural, por el hecho de que implica diferentes lenguas y culturas; III) interpersonal, practicado por parejas de aprendices; IV) socialmente simétrica, involucra la alternancia de roles, pues en determinado momento se puede ser aprendiz de la lengua del compañero, y en otro, profesor del propio idioma.

7 Nuestra traducción para "a aprendizagem em tándem consiste no intercâmbio e compartilhamento de conhecimento entre indivíduos de culturas diferentes, com propósitos de aprendizagem de línguas de modo colaborativo". 
El trabajo en tándem puede ser realizado desde diferentes perspectivas:

- Presencial, designado también cara a cara. La comunicación es predominantemente oral, pero los participantes, siempre que quieran, pueden recorrer a materiales escritos y también apuntar las informaciones;

- Por correo electrónico (e-mail), conocido también por e-tándem. Considerando que los participantes en e-tándem se encuentran en sitios diferentes, es difícil seguir las mismas pautas del tándem presencial;

- Teletándem, diferente del tándem presencial y del e-tándem, porque permite una interacción completa (escrita y audio-visual) en tiempo real entre los participantes, debido a programas de comunicación gratuitos a través de internet (RAMMÉ, 2014).

Independiente de la perspectiva adoptada, se trata de una posibilidad para una comunicación auténtica en la lengua meta. En este contexto, las informaciones negociadas respecto a la cultura, la forma de vivir, entre otros elementos de determinado país, provienen de una persona concreta, con su personalidad y percepción de todo lo que está en su entorno.

Es un complemento para la clase de LA, tanto si se realiza de forma presencial como por Internet. Aprender en tándem es una práctica realizada por intermedio de comunicación auténtica con un interlocutor nativo, que sirve de modelo y que puede corregir y auxiliar a la hora de expresarse. 
En su concepción actual y en sus muchas formas (en parejas, en grupos, en e-tándem, tándem presencial, teletándem, etc) el tándem se convirtió, antes de todo, en una actividad complementaria al proceso tradicional de aprendizaje de lenguas (en el aula, principalmente), pues pone los aprendices de lengua adicional en contacto con hablantes nativos de la lengua meta, proporcionando ambientes comunicativos auténticos en que estos pueden desarrollar sus habilidades sociocognitivas, interculturales y lingüísticas de manera plena e irrestricta (RAMMÉ, 2014).

El hecho de que ambos pueden, de alguna forma, hablar la lengua del otro, les permite la ayuda recíproca mediante explicaciones, comparaciones entre las culturas o esquemas lingüísticos. Además, cuando se establece una comunicación entre personas de diferentes comunidades de lenguas y de culturas, se facilita, igualmente el aprendizaje intercultural.

El tándem, como herramienta de aprendizaje de una lengua adicional, puede encuadrarse en las más recientes teorías sociointeraccionistas de enseñanza y aprendizaje. Vygotsky y Bajtín, influenciaron fuertemente la enseñanza de lenguas adicionales, cuando situaron la cultura y el lenguaje en la constitución social del hombre y del conocimiento. Para ambos, la lengua es producto de actividades sociales, resultantes de interacciones entre interlocutores, por lo tanto, la enseñanza de lenguas no puede dejar de considerar la lengua en contexto. En consonancia, el tándem se basa en el presupuesto de que en las interacciones entre los tandenistas el conocimiento (de la lengua, de la cultura del otro) es socialmente co-construido en la interacción entre los pares por intermedio del lenguaje (RAMMÉ, 2014). 
El desarrollo de la competencia intercultural se presenta como un importante factor con apoyo tecnológico. Siempre ha formado parte del aprendizaje de la lengua, pero actualmente ha adquirido una creciente importancia.

\section{La importancia de la mediación estratégica}

Varios investigadores consensuan en que las situaciones cotidianas de enseñanza y aprendizaje componen un proceso en el que existen interacciones dinámicas entre cognición, contexto y experiencia. En efecto, los contextos social, institucional, físico, por los cuales alumnos y profesores actúan, ejercen profundo impacto en sus cogniciones. Mejor dicho, el aprendizaje puede considerarse como procesual y socialmente mediado. Un concepto central para la comprensión del pensamiento de Vygotsky respecto al funcionamiento psicológico es el concepto de mediación.

Para ampliar nuestra concepción respecto a la mediación, presentaremos algunas definiciones que colaboran con el sentido adoptado en este estudio. Gehlen \& Delizoicov (2012) argumentan que mediación "se caracteriza como un proceso de intervención de un elemento intermediario en una relación que deja de ser directa y pasa a ser mediada por tal elemento ${ }^{8 \prime}(2012$, p.61).

De forma complementaria, Vieira-Abrahão (2012) presenta este concepto como primordial en la teoría sociocultural: "Es el proceso mediante el cual los seres humanos se

8 Nuestra traducción para "pode ser caracterizada como um processo de intervenção de um elemento intermediário numa relação que deixa de ser direta e passa a ser mediada por tal elemento" (p. 61). 
valen de artefactos culturalmente construidos, de conceptos y de actividades para controlar y transformar el mundo material o su propio mundo y sus actividades sociales y mentales recíprocamente ${ }^{9 \prime \prime}(2012$, p.5).

Vygotsky (2007) expone, en su obra, que la relación del hombre con el mundo no es una relación directa, sino fundamentalmente una relación mediada. Esta mediación se realiza a través de instrumentos y de signos. La mediación por instrumentos es la relación de las personas, usando herramientas que sirven de intermediarias con los elementos del mundo. A modo de ejemplo, podríamos citar el hacha, que tiene el potencial de cortar de manera más ágil que la mano humana y los útiles que permiten el acopio de agua. Luego, estos instrumentos hacen una mediación entre la acción concreta sobre el mundo y el mundo.

El concepto vygotskyano de mediación se relaciona directamente con la cuestión de la internalización "la internalización de las actividades socialmente arraigadas e históricamente desarrolladas constituye el aspecto característico de la psicología humana; es la base del salto cualitativo de la psicología animal para la psicología humana ${ }^{10 \prime \prime}$ (VYGOTSKY, 2007, p.76).

9 Nuestra traducción para: “É o processo por meio do qual os seres humanos se utilizam de artefatos culturalmente construídos, de conceitos e de atividades para regular (ganhar controle voluntário e transformar) o mundo material ou seu próprio mundo e suas atividades sociais e mentais reciprocamente (p.5).

10 Nuestra traducción para: "a internalização das atividades socialmente enraizadas e historicamente desenvolvidas constitui o aspecto característico da psicologia humana; é a base do salto qualitativo da psicologia animal para a psicologia humana" (VYGOTSKY, 2007, p.76). 
La invención y el uso de los signos como recursos auxiliares para solucionar un determinado problema psicológico, tales como acordarse, comparar, relatar, elegir, por ejemplo, son análogos a la invención y el uso de los instrumentos, sólo que ahora, en el ámbito psicológico. Los signos son formas posteriores de mediación de carácter semiótico (simbólico), que se interponen entre el sujeto y el objeto de conocimiento. El hecho de cambiar el anillo de dedo, por ejemplo, para que uno se acuerde que tiene que llamar a alguien, es una información de carácter simbólico que está interpuesta entre la intención de hacer algo y la propia acción. Esto, todavía, es concreto, aún es visible por otros, está marcado en el mundo fuera de nosotros, sin embargo, no es de carácter instrumental, sino de naturaleza simbólica, en el sentido de que no actúa directamente sobre las cosas, pero actúa en un plan simbólico.

Los signos aparecen en otro plan, pero este, totalmente simbólico. Los elementos son puestos dentro del sistema psicológico de las personas y funcionan como mediadores semióticos. Para tanto, aparece una característica intrínsecamente humana, que es la posibilidad de representación mental; la posibilidad de transitar por un mundo que es sólo simbólico.

Cuando vemos una silla no estamos relacionándonos con ella de manera no mediada, directa. Sólo la sentimos si la tocamos y la sentimos si es de madera, de plástico, de acero etc., o si nos sentamos en ella. La miramos y vemos "silla" inmediatamente. Ella nos remite a un objeto de carácter simbólico que ya está dentro de nuestra cabeza, que es el concepto de silla, la idea de silla, la palabra silla, la imagen silla. 
Sea cual sea la forma, hay una representación de los elementos del mundo que está dentro de nosotros, que no es el mundo, sino representaciones del mundo. Por tener el ser humano esta capacidad, podemos transitar entre dimensiones de tiempo, podemos pensar en momentos pasados, anticipar momentos futuros, podemos imaginar objetos o acciones en diferentes espacios, todo por intermedio de este plan simbólico, de estos mediadores que hacen ese puente entre nuestra persona y el mundo. Gran parte de la acción del hombre en el mundo es mediada por la experiencia de otros. No es necesario vivir todo en primera mano. Esto es esencial para los procesos de crecimiento histórico, de no ser así, cada ser humano tendría que empezar todo del punto cero.

En esta ocasión, creemos que, a partir de la visión que comulgamos en este texto, el complejo proceso de enseñanza y aprendizaje puede concebirse como mediación dialógica. Luego, "cuando la enseñanza propicia oportunidades de aprendizaje en que los individuos pueden participar en actividades que les proporcionan experiencias directas en el uso de nuevas herramientas psicológicas, estas tienen el potencial para funcionar como instrumentos poderosos"11 (SOUZA, 2014, p.78).

Otro concepto fundamental para comprender los procesos de mediación e internalización es el de la zona de desarrollo próximo (ZDP). Vygotsky (2007) presenta

11 Nuestra traducción para: "quando o ensino cria oportunidades de aprendizagem em que os indivíduos podem participar em atividades que lhes proporcionam experiências diretas no uso de novas ferramentas psicológicas, essas ferramentas têm o potencial para funcionar como instrumentos poderosos (SOUZA, 2014, p.78). 
este término como "la distancia entre el nivel de desarrollo real, que suele determinarse a través de la solución independiente de problemas bajo la orientación de un adulto o en colaboración de compañeros más capaces"12 (p.97). En otras palabras, a modo de ejemplo, este concepto expone que lo que un niño puede hacer hoy con la ayuda de un adulto será lo que conseguirá hacer solo en el futuro.

Souza (2014) complementa que la ZPD puede ser definida como la diferencia entre qué puede alcanzar una persona de forma independiente y qué puede conseguir trabajando en colaboración con otras personas o con un mediador más capaz. El autor recurre a Jonhson ${ }^{13}$ (2009) y argumenta que cuando reconocemos la ZDP como:

Multidimensional y dinámica y como lugar de crecimiento potencial, debemos ofrecer a los alumnos instrumentos de mediación estratégicos, en

12 Nuestra traducción para: "a distância entre o nível de desenvolvimento real, que se costuma determinar através da solução independente de problemas, e o nível de desenvolvimento potencial, determinado através da solução de problemas sob a orientação de um adulto ou em colaboração com companheiros mais capazes" ( $p$ 97).

13 Nuestra traducción para: multidimensional e dinâmica e como lugar de crescimento potencial, devemos oferecer aos alunos instrumentos de mediação estratégicos, em vez de instrumentos fixos ou aleatórios. Isto, entretanto, é difícil de ser executado nas escolas onde os instrumentos de mediação disponibilizados para os professores tendem a ser formalizados (livros didáticos), fixos (técnicas educacionais específicas), e rotinizadas (normas escolares) (p. 20). 
lugar de instrumentos fijos o aleatorios. Eso, sin embargo, es difícil de ejecutarse en las escuelas donde los instrumentos de mediación disponibles para los profesores tienden a ser formalizados (libros de texto), fijos (técnicas educacionales específicas), y rutinarios (normas escolares) (p. 20).

De esta manera, en nuestra investigación, consideramos fundamental buscar una comprensión amplia de las TDICS y de los docentes como instrumentos de mediación para el desarrollo de la capacidad comunicativa en una perspectiva discursiva, vía diálogo y promoción de la alteridad.

\section{Algunas cuestiones metodológicas}

Apoyados en la experiencia de Souza (2014), entre los diversos caminos para el avance de la investigación científica, nos afiliamos a la investigación cualitativa de carácter etnográfico a causa de sus contribuciones para la comprensión del ámbito educativo y pedagógico, en que las relaciones humanas y las diversas variables juegan un papel muy relevante. En efecto, la investigación se vuelve compleja y demanda una metodología que contenga conceptos, instrumentos y procedimientos que describan y analicen esa realidad adecuadamente.

Buscando comprender las potencialidades y limitaciones de la investigación etnográfica en contextos de enseñanza y aprendizaje de lenguas adicionales, contamos con Cançado (1991) y, para la comprensión de la 
metodología de la investigación de creencias en el contexto de la enseñanza y aprendizaje de lenguas nos apoyamos en Barcelos (2001) y Vieira-Abrahão (2006).

El paradigma cualitativo posee una orientación sociocultural, que enfatiza los factores externos y sociales. Los fenómenos se investigan in situ, en el mismo contexto social donde ocurren. No se vale de datos numéricos de la realidad, sino que trata de interpretarla y describirla minuciosamente a través de la palabra. Tenemos como ejemplo: los apuntes de campo, los diarios, los informes basados en la observación y las entrevistas.

En este contexto, la investigación cualitativa se interesa por el significado de las acciones humanas y de la vida social en general, y está orientada a la manifestación, interpretación y comprensión de los fenómenos:

El interés de los educadores por ese método de investigación comenzó a finales de los años setenta, pues se necesitaba un estudio minucioso en el ámbito de lo cotidiano escolar. Estudiosos del área destacan que una característica importante de la investigación etnográfica es el énfasis en el proceso, en lo que está sucediendo y no en el producto o en los resultados finales (SOUZA, 2014, p. 42). ${ }^{14}$.

14 Nuestra traducción para: $\mathrm{O}$ interesse dos educadores por esse método de pesquisa começou no final dos anos 70 , pois se necessitava de um estudo que fosse minucioso no âmbito do dia a dia escolar. Pesquisadores da área destacam que uma 
Así pues, nuestra investigación busca conocer el rol de la mediación y sus posibles contribuciones en el proceso de enseñanza y aprendizaje del portugués y del español como lenguas adicionales en la interacción entre brasileños y nativos hispánicos, aprendices de portugués, vía teletándem.

\section{A Modo de Cierre}

La presente investigación se encuentra, todavía, en estadio embrionario. Sin embargo, en un contexto como el que describimos a lo largo de este trabajo, existen indicios de que las TDICS y los docentes participantes actúan como mediadores útiles e imprescindibles cuando proporcionan la interacción de los aprendientes a la distancia de forma colaborativa.

A modo de ilustración de lo que se ha visto y discutido hasta aquí, presentaremos un trecho del relato espontáneo de una participante del proyecto:

Antes de comenzar a participar con el proyecto de teletándem pensaba que el mismo iba a ser complicado de llevar a cabo, dada la distancia geográfica que existe entre alumnos y la imposibilidad de pensar el aprendizaje "cara a cara". Nunca antes había participado de una experiencia de

característica importante da pesquisa etnográfica é a ênfase no processo, naquilo que está ocorrendo e não no produto ou nos resultados finais (SOUZA, 2014, p. 42). 
este tipo. Cabe aclararse el motivo: es la primera vez que en Salta se da algo así. Sin embargo, en la medida en que se fueron dando las charlas con mis compañeros (primero con Juan y después con Janice) me di cuenta de que el interés (mutuo) por estudiar y perfeccionar una segunda lengua es lo que nos lleva a eliminar esas barreras geográficas. El potencial de las TIC nos permite estar conectados en tiempo real, realizar video llamadas, escuchar al otro y hacer que nos escuchen. Las herramientas de Internet nos permiten además hacer uso de material audiovisual (en mi caso encuentro un gran potencial en los videos, los poemas hablados, las películas, entre otros). Estas herramientas ayudan en el proceso de aprendizaje y nos permiten conocer al otro de una manera más dinámica. Por ejemplo, con Janice intercambiamos películas nacionales... Ella me sugirió una película brasilera y yo, una argentina. A través de esas producciones cinematográficas uno puede ir aprendiendo de la cultura del país vecino, puede apropiarse de las expresiones idiomáticas y observar paisajes hermosos, captados por la cámara. La barrera geográfica se hace cada vez menor al saber que hay 
intereses en común con la persona que está del otro lado de la pantalla, con las mismas ganas de aprender y de mostrar su propia cultura (Dafne, información verbal).

El fragmento presentado por la participante del proyecto señala que la creencia de que aprender lenguas adicionales no funciona a la distancia por motivos geográficos y falta de contacto "cara a cara", se destruye a lo largo del proceso y da lugar a la creencia de que, con la mediación de las TDICS, la barrera geográfica es cada vez menor, desde que haya intereses en común en la pareja para favorecer el aprendizaje.

A partir de nuestro objetivo de exponer los estudios preliminares de nuestro proyecto de investigación que mira analizar el rol de la mediación en la interacción entre aprendientes de español y portugués como lengua adicional en el contexto de las prácticas del teletándem, nuestro recorrido, en este capítulo, ha comenzado con la presentación de dos de los participantes que nos motivan a avanzar en nuestras prácticas e investigaciones y que dan sentido, por lo tanto, a nuestras acciones en la enseñanza, en la investigación y en la extensión.

A lo largo de esta exposición, presentamos también, conceptos como tándem, teletándem, mediación y, entre otros, nuestra concepción de investigación cualitativa de carácter etnográfico, que ha orientado nuestra investigación de campo.

Hasta ahora, las conclusiones no son definitivas y estamos aún en fase de recolección de datos y de análisis preliminares. No obstante, podemos destacar que tenemos, 
en relación a este proyecto, entusiásticas expectativas y esperamos que colabore para el desarrollo de aprendientes interculturalistas sensibles a los procesos discursivos vehiculados en y por el lenguaje y capaces de promover la integración latinoamericana.

\section{REFERENCIAS}

ALMEIDA FILHO, J. C. P. Dimensões comunicativas no ensino de línguas. Campinas: Pontes, 1993.

ARNOUX, E. N. Representaciones sociolingüísticas y construcción de identidades colectivas en el Mercosur. In: CELADA, M.T. et al. Lenguas en un espacio de integración: acontecimientos, acciones, representaciones. Buenos Aires: Biblos, 2010.

BARCELOS, A. M. F. Metodologia de Pesquisa das Crenças sobre Aprendizagem de Línguas: Estudo da Arte. Rev. Brasileira de Lingüística Aplicada, v.1, n.1, p.71-92, 2001.

BARCELOS, A. M. F. Cognição de professores e alunos: tendências recentes na pesquisa de crenças sobre ensino e aprendizagem de línguas. In: Barcelos, A. M. F.; VIEIRAABRAHÃO, M. H. (Orgs.) Crenças e ensino de línguas: foco no professor, no aluno e na formação de professores. Campinas: Pontes, 2006, p.15-42.

BENEDETTI, A. M. Dos princípios de tándem ao teletándem. In: BENEDETTI, A.M.; CONSOLO, D.A.; VIEIRA-ABRAHÃO, M.H. (Orgs.). Pesquisas em Ensino e Aprendizagem no Teletándem Brasil: línguas 
estrangeiras para todos. Campinas: Pontes Editores, 2010, v.1, p. 21-46.

CANÇADO, M. Procedimentos de Pesquisa Etnográfica em Sala de Aula de Língua Estrangeira: avaliação das potencialidades e limitações da metodologia. Dissertação (Mestrado em Estudos Linguísticos). Belo Horizonte: UFMG, 1991.

CHAREILLE, Samantha. Planificación lingüística y constitución de un bloque regional: El caso del Mercosur (Argentina, Brasil, Paraguay y Uruguay) y de Chile. In: Language Problems \& Language Planning, v. 27, n.1, 2003, p.63-70.

GEHLEN, S. T.; DELIZOICOV, D. A dimensão epistemológica da noção de problema na obra de Vigotski: implicações no ensino de ciências. Investigações em Ensino de Ciências, v.17, n.1, p.59-79, 2012.

JOHNSON, K. Second Language Teacher Education: a sociocultural perspective. New York: Routledge, 2009.

KRASHEN, S.D. Principles and practice in second language acquisition. N.Y.: Pergamon Press, 1982.

OLIVEIRA, M.K Vygotsky, aprendizado e desenvolvimento, um processo sócio-histórico. São Paulo: Scipione, 2006.

RAMMÉ, V. Tándem: guia para uma aprendizagem solidária. Curitiba: Valdilena Rammé, 2014. Disponible en: $<$ http://www.teletandembrasil.org/home.asp>. Accesso en: 14 de feb. 2015. 
REVUZ, C. A língua estrangeira entre o desejo de um outro lugar e o risco do exílio. In: SIGNORINI, Inês (Org.) Lingua(gem) e identidade: elementos para uma discussão no campo aplicado. Campinas: Mercado das Letras; São Paulo: Fapesp, 1998, p.213-230.

SOUZA, Fábio Marques de. Espanhol-língua estrangeira para brasileiros: políticas de difusão e formação de professores no Estado de São Paulo. Dissertação (Mestrado em Educação) - Faculdade de Filosofia e Ciências, Universidade Estadual Paulista, 2009.

SOUZA, Fábio Marques de. O cinema como mediador na (re)construção de crenças de professores de espanhol-língua estrangeira em formação inicial. Tese (Doutorado em Educação: cultura, organização e educação) - Faculdade de Educação da Universidade de São Paulo: USP, 2014.

SOUZA, F. M. A sétima arte como artefato semiótico mediador das reflexões a respeito de como de aprende uma língua adicional. Revista Hispanista (Edição em Português), 2015a.

SOUZA, F. M. Teletándem UEPB. Projeto de Extensão. Campina Grande: PROEX/UEPB, 2015b.

SOUZA, F. M. Tecnologias como mediadoras do processo de ensino-aprendizagem numa perspectiva sociocultural. Projeto de Pesquisa (Pós-doutorado em Educação Contemporânea). Caruaru: UFPE, 2015c.

GARCIA DE STEFANI, V. C. O cinema na aula de língua estrangeira: uma proposta pedagógica para o 
ensino-aprendizagem de espanhol. Dissertação (Mestrado em Linguística). São Carlos: UFSCar, 2010.

VIEIRA-ABRAHÃO, M. H. Metodologia na investigação das crenças. In: BARCELOS, A.M.F.; VIEIRA-ABRAHÃO, M. H. (Orgs.) Crenças e ensino de línguas: foco no professor, no aluno e na formação de professores. Campinas: Pontes, 2006, p.219-231.

VIEIRA-ABRAHÃO, M. H. A formação do professor de línguas estrangeiras de uma perspectiva sociocultural. Signum. Estudos de Linguagem, v.15, p. 457-480, 2012.

VYGOTSKY, L.S. A formação social da mente: o desenvolvimento dos processos psicológicos superiores. Tradução: José Cipolla Neto et al. São Paulo: Martins Fontes, 2007.

WOODS, D. Teacher cognition in language teaching: beliefs, decision-making and classroom practice. Cambridge: CUP, 1996.

WOODS, D. The social construction of beliefs in the language classroom. In: KALAJA; P; BARCELOS. A. M. F. (Ed.). Beliefs about SLA: New Research Approaches. Dordrecht: Kluwer, 2003. p. 201-229. 